\title{
COMUNICAÇÃO E ESTADO DEMOCRÁTICO
}

COMMUNICATION AND DEMOCRATIC STATE

\author{
MURILO CÉSAR RAMOS \\ Pós-Doutorado pela Universidade Estadual de Campinas, \\ Brasil (1994). Doutor em Comunicação pela \\ University of Missouri-Columbia, Estados Unidos (1982) \\ Professor Adjunto IV da Universidade de Brasília (UnB) , Brasil
}

\section{RESUMO}

A política de comunicação é sempre um vetor significativo na relação Estado / Comunicação, no entanto isto não é apenas afirmar um direito; o direito à comunicação, que inverte e amplia a idéia clássica do direito à informação. Fazer política de comunicação é, sobretudo, fortalecer a própria idéia do Estado democrático de direito, não ignorando o valor social do trabalho. Fazendo uma leitura sobre diversos autores clássicos o artigo consegue amplia as reflexões sobre questões políticas atuais e centrais na sociedade.

Palavras-chave: Comunicação; estado democrático; política

\section{ABSTRACT}

The communication policy is always a significant vector in the State/ communication, however this is not just a state law, the right to communication, which reverses and amplifies the classical idea of the right to information. Making communication policy is, above all, strengthen the very idea of democratic rule of law, not ignoring the social value of work. Doing a reading of several classical authors the article extends ideas on current political issues and central in society.

Keywords: Communication; state democratic; politics.

Para falar da relação entre Comunicação e Estado Democrático, e de Comunicação como Política Social, começo falando de política.

Política é ruído, política é conflito. Política está muitas vezes próxima do caos.

A política é o terreno dos homens, com tudo o que de bom e de ruim sua humanidade lhes dá.

Ao reverso da política está a técnica; seu terreno é o da ordem, do controle, da previsibilidade.

A técnica, nesse sentido, seria um campo mais propício a deuses, cujos poderes lhes permitiriam sempre a perfeição.

E é como deuses que muitos 
1 Perry Anderson, "Friedrick von Hayek: A direita intransigente no fim do século", In Afinidades Seletivas. São Paulo: Boitempo Editorial, 2002, p. 320.

2 Idem, p 325.

3 Idem, p. 328.

4 Norberto Bobbio. "A Política". In Norberto Bobbio: o Filósofo e a Política - Antologia. Por José Fernández Santillán (Org.). Rio de Janeiro: Contraponto, 2003, p. 140.

5 Marco Aurélio Nogueira. Em Defesa da Política. São Paulo: Editora Senac, 2001, p. 29. especialistas se sentem quando chegam às fronteiras do conhecimento em suas áreas de saber, como, por exemplo, a da física nuclear, que gera artefatos capazes de em poucas horas, se usados em sua plenitude, dar fim à experiência da humanidade sobre a face da Terra.

Mas, nos dias de hoje, em que a ameaça da destruição nuclear em massa parece ter se ido com o desmonte da União das Repúblicas Socialistas Soviéticas e o fim da Guerra Fria nos anos 90 do século $\mathrm{XX}$, a técnica potencialmente mais destrutiva pode estar presente, não obstante o caráter hiperbólico dessa afirmação, nas hipóteses sociais e nas ferramentas matemáticas da ciência econômica que oferece suporte ao neoliberalismo.

Ciência econômica que, graças ao cérebro brilhante do economista e filósofo social Friedrick Hayek, transformou-se na ideologia política global dominante na passagem do século XX ao XXI, resultado da conjunção intelectual do que Perry Anderson (2002, p. 320) chamou de o "mais importante quarteto de teóricos europeus da direita intransigente", na transição dos séculos XIX e XX (ênfase minha): o austríaco Hayek (1899-1991), o historiador britânico Michael Oakeshott (1901-1990), o jurista alemão, Carl Schmitt (1888-1985); e o filósofo alemão, Leo Strauss (1899-1973). ${ }^{1}$

Para Strauss, por exemplo:

Uma ordem política justa deve se basear nas exigências imutáveis do direito natural. A natureza, entretanto, é inerentemente desigual. A capacidade de descobrir a verdade está restrita a uns poucos, e a de aceitála a uns poucos mais. Portanto, o melhor regime deverá refletir as diferenças em excelência humana, e ser governado por uma elite apropriada (ANDERSON, 2002, p. 325). ${ }^{2}$

Para Michael Oakeshott, a política seria uma atividade de segunda categoria; por isso, entendia que política e filosofia tinham que ser categoricamente separadas. Política, segundo ele, envolvia intrinsecamente "vulgaridade mental, lealdades irreais, objetivos ilusórios e falsas significâncias" (ANDERSON, 2002, p. 328; grifo nosso). ${ }^{3}$

Desde que na Antiguidade Clássica, na Grécia e em Roma, começou-se a pensar e a praticar a democracia e a república - formas ocidentais de conquista e exercício do poder de governo por camadas aristocráticas ampliadas, em oposição ao poder autocrático de soberanos -, o dilema se instalou: como assegurar a boa prática da política, do governo em nome de todos e para o bem de todos, se os políticos, se os homens e, eventualmente, também as mulheres, investidos do poder de governar, tendem invariavelmente a pensar mais no seu próprio bem do que no bem comum? (BOBBIO, 2003, p. 140)

"A política", escreveu Marco Aurélio Nogueira, solicita uma concessão difícil de ser feita: ela pede que os indivíduos e os grupos saiam de si mesmos, moderem-se, ultrapassemse, ponham-se na perspectiva dos demais. Seu grande desafio é criar as condições para que se passe da defesa dos interesses particulares para a construção e a defesa do interesse geral (NOGUEIRA, 2001, p. 29). ${ }^{5}$

Daí que a idéia do governo dos homens bons, de elite, com excelente formação em todos os cam- 
pos da atividade humana necessária à condução dos destinos de outros homens menos privilegiados, sempre rondou a discussão teórica e prática da democracia. Idéia que se tornaria mais forte na medida em que o governo evoluía para formas progressivamente mais complexas de representação eleitoral parlamentar e executiva, e de alternância de poder.

Mas, esta é uma idéia, como vimos, historicamente associada à reação do pensamento conservador.

"Não é possível pensar a política", acentua Nogueira (2001, p. 44, grifo nosso),

o governar, o administrar, o decidir, como um ato e um espaço submetidos a rígidos controles técnicos (...) O predomínio unilateral e autônomo dos técnicos - a autoridade dos especialistas - empurra os cidadãos para os bastidores da decisão política. Corrói e enfraquece a democracia. Os técnicos e seus conhecimentos serão sempre bem-vindos ao campo do governar, do decidir e do administrar, mas desde que se submetam a uma pers-pectiva maior, que os engloba e disciplina. Se não podemos nem devemos querer dispensar os especialistas, temos de saber como impedir que eles se substituam a todos os demais e colonizem o espaço da política. ${ }^{6}$

Ainda citando Nogueira (2001), "A principal função da política é dar perspectiva às pessoas - tornar autoconsciente uma comunidade". Mas,

[...] a dimensão técnica da vida conspira contra a política. São tantos e tão complexos os prob- lemas com que se defrontam as comunidades modernas, que o recurso aos peritos tornou-se inevitável. $O$ arsenal com que se opera no círculo das decisões nos intimida e oprime (NOGUEIRA, 2001, p. 47). ${ }^{7}$

Em decorrência, acrescenta, "o cidadão perde terreno para o especialista, que se converte no personagem central da vida política", como observou Norberto Bobbio (2007, p. 46). ${ }^{8}$

No entanto, apesar da pertinente observação de Bobbio (2007), quando se estuda política e governo, não são os técnicos que nos desafiam; não estão neles, em geral, as chaves que nos ajudam a compreender melhor a relação entre povo, sociedade e história.

De José Bonifácio a Joaquim Nabuco; de Rio Branco a Ruy Barbosa; de Getúlio Vargas a Jango, Jânio e Juscelino; de Tancredo Neves a Ulysses Guimarães a Leonel Brizola; de Fernando Collor de Mello a Luiz Inácio Lula da Silva, passando por José Sarney, Itamar Franco e Fernando Henrique Cardoso: grandes referências nacionais, este é um processo que encontra similares em todos os países, vêm do ambiente complexo e contraditório da política, e não da especialização técnica. Se em suas vidas, cada um deles, nas funções parlamentares e legislativas que exe-cutaram, contaram com a colaboração sistemática de assessores, com formação técnica especializada nos mais diversos campos, suas contribuições à vida social resultaram da circunstância de terem sido seres políticos por definição e essência. E aqui não se faz juízo de valor sobre suas qualidades pessoais para o exer-
6 Marco Aurélio Nogueira. Em Defesa da Política. São Paulo: Editora Senac, 2001, p. 44.

7 Idem, p. 47.

8 Norberto Bobbio. O Futuro da Democracia. São Paulo: Paz e Terra, 2000, 7 ạ ed., p. 46.

9 Ver Luciano Gruppi, Tudo Começou com Maquiavel. Porto Alegre: L\&PM, 1986. 
cício das funções para que tenham sido eleitos ou designados.

Nicolau Maquiavel, o seminal pensador italiano que, em $O$ Príncipe, assentou as bases conceituais e teóricas para o que viria a ser a politicologia moderna, estabeleceu para os governantes duas características essenciais: virtú e fortuna. A primeira diz respeito às qualidades pessoais do governante, que o credenciariam para o exercício do poder de soberano; entre elas qualidades morais e éticas. A segunda deriva de uma circunstância fora do alcance do soberano, e diz respeito mais â conjuntura do seu tempo e as realidades objetivas materiais de que poderá dispor; fortuna aqui tem o sentido da sorte. Observa-se que o primeiro e, por isso, até hoje, o mais importante teórico, e conselheiro, de homens de governo, não se ocupou de qualidades técnicas específicas que seriam essenciais ao exercício do poder.

Lancemos nossos olhos por um momento para o terceiro poder das democracias modernas, o Judiciário. Quem consegue lembrarse, no Brasil, de um membro de tribunal superior que tenha alcançado a dimensão social e pública dos brasileiros mencionados acima, que fizeram suas vidas políticas nos poderes executivo ou legislativo?

A Justiça ostenta um distanciamento muito grande da vida das pessoas, que pode ser explicado, de um modo positivo, pelo caráter essencialmente técnico que devem ter as decisões do juiz.

Não seria por outra razão que a 10 Ver Boaventura de Sousa Santos. Introdução a uma Ciência Pós Moderna. Rio de Janeiro: Graal, 1989. imagem popular da Justiça é o de uma mulher, que tem em uma das mãos uma balança em equilíbrio, na outra uma espada, e nos olhos uma venda. A mulher é a mãe, justa, capaz de punir sem favorecimentos, porque cega aos interesses conflitantes de seus filhos e filhas, sejam ricos ou pobres. Há, porém, um outro modo, não tão positivo, de se ver esse distanciamento entre a justiça e o cotidiano das pessoas, em que ela aparece despida da venda e livre da balança, embora não da espada. A justiça, não obstante seu desígnio do cumprimento cego da lei, sem distinção entre aqueles a que se deve aplicá-la, é também toda ele permeada pelas contradições e ambigüidades da Política. Mas, na sua insistência, ideológica, de se ver, e se apresentar, como o mais técnico dos poderes democráticos, pode estar a explicação mais lógica da distância que existe, aqui e em outros lugares, entre a justiça e a cidadania. Esta é uma lógica que se constata na própria linguagem de que se vale a justiça para construir, aplicar e explicar suas decisões. Uma linguagem que de tão, desnecessariamente, técnica, torna incompreensíveis à pessoa comum as suas ações, o que já não é, em geral, o caso dos poderes executivo, e principalmente do legislativo.

A correção técnica, não importa a complexidade do problema tratado, pode sempre ser traduzida em linguagem acessível à maioria das pessoas minimamente educadas. A aplicação sistemática de jargões não é um imperativo científico. É a isso que Boaventura de Sousa Santos (1989) se refere, quando nos fala de uma dupla ruptura epistemológica. ${ }^{10}$ Segundo ele, ciência e senso comum interpenetram-se o tempo todo, mas a aventura científica não se faz apenas com o conhecimento do dia a dia, com suas explicações singelas sobre os problemas da vida e da natureza. Mas, o cientista, em 
especial o cientista social, se rompe epistemologicamente com o senso comum, para com teoria e método buscar a verdade das coisas, ao descobri-la, ou dela se aproximar, tem o dever ético de praticar a segunda ruptura, de modo a poder devolver ao senso comum toda a profundidade de suas descobertas.

Por isso, quando os praticantes de um corpo de conhecimento social passam a operar seu ofício de um modo que o afasta do alcance da maioria das pessoas, isto pode ocorrer por duas razões principais: ou o praticante tem escasso domínio do ofício, a ponto de não conseguir explicá-lo sequer para si, quanto mais para outros; ou o praticante tem pleno domínio do ofício, mas quer mantê-lo fora do alcance do outro. E o faz, em geral, como forma de acumular poder sobre o outro, e assim melhor dominá-lo.

Em nenhum outro campo da ciência social isto é mais verdadeiro hoje do que na economia. Adam Smith, a quem pode se atribuir a origem do pensamento econômico liberal que serve hoje de sustentação ideológica ao neoliberalismo, antes de escrever a sua seminal investigação sobre a natureza e causa da riqueza das nações, ${ }^{11}$ produzira, com dezessete anos de antecedência, uma obra dedicada a teorizar sobre a relação entre acumulação de riqueza e sentimentos morais. ${ }^{12}$ A preocupação de Smith com uma teoria de sentimentos morais, com o sentido ético das orientações econômicas, não é comumente encontrada na agenda dos economistas contemporâneos dedicados a pregar a supremacia de uma teoria de laissez faire sustentada por complexos modelos matemáticos de explicação e previsão, dos quais a mera idéia de uma moral econômica está sumariamente afastada. Como afastada está, por razões similares, até mesmo a idéia clássica de uma economia política.

A política vive, hoje, não obstante toda a argumentação que possamos fazer em seu favor, uma crise profunda, que não decorre apenas do duro julgamento que o senso comum dela faz, mercê da desconfiança que tem dos políticos profissionais e suas práticas egoístas, quando não abertamente venais. Isto é particularmente sensível em uma realidade política como a brasileira, permeada por uma tradição de compadrio, de clientelismos e de relações fisiológicas no trato com a coisa pública, mercê de insuportáveis, porque deliberadas, misturas entre o público e o privado. Nossos políticos profissionais não são, como de resto tantos em todo o mundo, exemplos de retidão moral e comportamento ético na gestão do bem comum. Isto, entretanto, não é suficiente para explicar a profundidade da crise da Política em nosso tempo. Bons e maus políticos existiram sempre, e jamais deixarão de existir. Como dito acima, a política é terreno dos homens, e não de divindades ungidas pela perfeição de caráter.

Acrise da política em nosso tempo é também de natureza ideológica, programática. A origem dessa crise está na falência da experiência comunista da União Soviética, que pareceu ter levado de arrasto no final do século XX a histórica divisão política entre esquerda e direita. Ali, pareceu ter ficado sem sentido o argumento de Nogueira de que "a política é o principal ins-trumento para que se possa pensar o social como espaço organizado:
11 Adam Smith, An Inquiry into the Nature and Causes of the Wealth of Nations. New York: Modern Library (edição original: 1776).

12 Idem, The Theory of Moral Sentiments. Indianapolis: Liberty Classics (edição original: 1759). 
13 Ver Francis Fukuyama, O Fim da História e o Último Homem. São Paulo: Rocco, 1992.

14 Anderson, "Friedrick von Hayek: A direita intransigente no fim do século", ibid. p. 332. espaço instituído, construído, articulado por conflitos, antagonismos e hegemonias". Afinal, conflitos, antagonismos e hegemonias estavam varridos para o limbo de uma História que atingira seu fim. ${ }^{13}$ Já não mais seriam necessárias as razões antagônicas, a explicitação das diferenças. O liberalismo político triunfara, mas não só ele; o capitalismo econômico era insubstituível como forma final de organização social. A forma das sociedades democráticas de mercado, pelo mercado e para o mercado. Se vivo, Friedrick Hayek já não precisaria mais ponderar que "um regime autoritário que reprimisse o sufrágio popular, mas respeitasse o domínio do direito, poderia ser melhor guardião da liberdade do que um regime democrático sujeito às tentações de intervenção econômica ou de distribuição social". ${ }^{14}$

Esse 'Estado de Direito não democrático', por paradoxal e contraditório que seja, é síntese perfeita do ideário neoliberal mais radical, pela negativa absoluta que contém da necessidade da política para a condução da economia. Ele seria o Estado de Direito revestido do dever legal único de assegurar a liberdade dos mercados. Um Estado de capitalistas e consumidores, sem qualquer possibilidade de mediação social conduzida pelas idéias de direitos humanos e de cidadania. De algum modo, essa perspectiva, que pode limpidamente ser qualificada de reacionária, porque mais do que conservadora, materializou-se, nas décadas de 80 e 90 do século $\mathrm{XX}$, em regimes autoritários do capitalismo periférico asiático e latino-americano, na Indonésia, Malásia, Hong Kong, Tailândia, e Chile, por exemplo. Ironicamente, nesse início do século XXI, ela é a perspectiva dominante na economia da China, a que mais cresce no mundo, sob o domínio de um hipotético partido comunista.

Aidéia de democracia política, no entanto, tornou-se contemporaneamente uma força hegemônica e, livre da pressão que sobre ela fazia o autoritarismo soviético, impôs-se sobre o mundo no final do século, impulsionada pelo liberalismo moderno irradiado dos países capitalistas centrais. A esses não fazia mais sentido, econômico inclusive, impor ditaduras impopulares, por isso instáveis, na sua periferia, uma vez que fora vencido o inimigo soviético, e deixara com ele de existir o perigo comunista. Também aqui a História parecia encontrar um fim. Suposto fim que veio na forma de uma nova hegemonia liberal, despida das concessões econômicas sociais que, pela via da social democracia, se vira forçada a fazer no processo de enfrentamento do comunismo. Hegemonia que representou o fim do Estado de Bem Estar keynesiano, com suas políticas de compensação social, e sua crença na Organização das Nações Unidas como as instituições mais aptas a promover o desenvolvimento em todo o mundo. Instituições como a Unesco (United Nations Education, Science and Culture Organization), FAO (Food and Agriculture Organization), IWO (International Work Organization), WHO (World Health Organization), Unctad (United 
Nations Conference for Trade and Development), foram substituídas progressivamente pelo Fundo Monetário Internacional (FMI), Banco Mundial (Bird) e Organização Mundial do Comércio (OMC), como os foros privilegiados de estruturação capitalista. Se na ONU, excetuado o Conselho de Segurança, com o dispositivo de veto atribuído aos raros países membros, ${ }^{15}$ prevalecia a idéia democrática de um país um voto, junto com a idéia de desenvolvimento pela base, nos novos foros tipicamente econômicos prevaleceria a lógica financeira e/ou mercantil, que assegura o poder de decisão aos participantes economicamente mais fortes. Isto é particularmente verdadeiro nos casos do FMI e Banco Mundial, que são instituições financeiras em sentido estrito, controladas de direito pelos principais fornecedores de seus capitais, os países mais ricos do mundo, reunidos no foro G-8 (Estados Unidos, Canadá, Grã-Bretanha, Alemanha, França, Itália, Japão e Rússia), sob a hegemonia incontestável dos Estados Unidos, com sua crença no desenvolvimento pelo topo.

Foi, portanto, nesse cenário que se impôs o modelo de reestruturação econômica capitalista neoliberal hayekiano, mas associado à idéia de democracia política para todos. Era um modelo que para se tornar hegemônico, por exemplo, na América Latina, não poderia mais depender de ditaduras brutais como a de Augusto Pinochet no Chile. Mas que, para isso, precisaria promover o divórcio conceitual entre economia e política. Aquela seria o ter- reno dos semideuses científicos portadores da sabedoria técnica, preferencialmente, matemática que tudo pode antever, ver e prever no reino das necessidades humanas. Já a política seria o reino, tolerado, dos homens e mulheres imperfeitos, muitos dos quais irremediavelmente desonestos, submetidos periodicamente ao escrutínio de outros homens e mulheres igualmente imperfeitos, incapazes por definição de, a não ser por acaso, fazer as escolhas eleitorais mais adequadas aos interesses do capital.

Movo agora minha atenção da política em seu sentido teórico, mais geral, para junto do Estado brasileiro, e as relações deste Estado com as instituições de comunicação.

Para frisar esta atenção, relembro o Artigo $1^{\circ}$ de nossa Constituição Federal:

"A República Federativa do Brasil, formada pela união indissolúvel dos Estados e Municípios e do Distrito Federal, constitui-se em Estado democrático de direito e tem como fundamentos:

I - a soberania;

II - a cidadania;

III - a dignidade da pessoa humana;

IV - os valores sociais do trabalho e da livre iniciativa;

$\mathrm{V}$ - o pluralismo político.

Parágrafo único. Todo o poder emana do povo, que o exerce por meio de representantes eleitos ou diretamente, nos termos desta Constituição."

Cidadania, dignidade da pes
15 São membros permanentes do Conselho de Segurança da ONU os Estados Unidos, França, Grã-Bretanha, Rússia e China. 
soa humana, valores sociais do trabalho e da livre iniciativa.

Meu argumento central hoje aqui, ao pensar a relação entre Estado democrático e comunicação, será o de que o ambiente institucional vigente para a comunicação social brasileira, que defino como regulamentarmente disperso e politicamente fragmentado, ignora o valor social do trabalho e privilegia quase que exclusivamente a livre iniciativa.

Isto acontece porque nossos supostos liberais encastelados no comando das empresas e conglomerados de comunicação simplificam a relação negativa original que assinalou a dialética Estado e comunicação e argumentam que qualquer ação positiva nesse campo equivale ao exercício puro e simples da censura. Ao assim agirem transformamse em fariseus contemporâneos, ignorantes, conscientes ou não, de como as instituições de comunicação vêm sendo forjadas ao longo de sua história.

O Estado democrático de direito de hoje é uma antítese, ainda em processo, dos absolutismos e totalitarismos de ontem e anteontem. Ontem e anteontem, os poderes totalitários e absolutistas negavam qualquer direito individual, quanto mais coletivo, entre eles, e por vezes principalmente, o da livre expressão política e religiosa. Em sua seminal obra, Mudança Estrutural da Esfera Pública, Jürgen Habermas demonstrou como uma burguesia revolucionária construiu durante décadas sucessivas, entre os séculos XVII e XVIII, uma esfera pública de opiniões políticas, decisiva para a afirmação de um novo poder secular e idealmente democrático. Mas, ele próprio afirmou na mesma obra a mudança estrutural dessa esfera pública que, já no final do século XIX, era dominada por despolitizados interesses privado-comerciais.

Quando os fundadores dos Estados Unidos da América inscreveram na Carta de Direitos anexada à sua constituição federativa uma primeira emenda que impediu o poder legislativo de fazer leis restringindo a liberdade de imprensa, entre outras negações, assim o fizeram na perspectiva de uma imprensa política, partidária, fundamental para a vitória da causa da independência e da república. Eles não anteciparam a mudança estrutural que nela ocorreria, que tornaria o mercado e o consumo predominantes sobre o Estado e a política.

É por isso que, nos Estados Unidos, mesmo sem uma lei de imprensa, os tribunais, em suas diversas instâncias, compuseram, desde o século XIX, um vasto corpo de jurisprudência positiva, para afirmar direitos contra abusos corporativos que ferissem a dignidade de cidadãos e cidadãs.

Daí o farisaísmo do nosso patronato da comunicação social quando se esconde atrás da defesa da liberdade de imprensa contra a censura cada vez que alguma iniciativa toma corpo na sociedade em favor da afirmação pelo Estado de direitos cidadãos no campo da comunicação social.

Mas, quando se trata de obter do Estado tratamento diferenciado para suas demandas econômicas, financeiras, tributárias, regulamentares e regulatórias, esse mesmo patronato não se vexa em exercer todo o poder de pressão de que dispõe para assegurar privilégios.

Tomemos aqui apenas o exemplo mais recente - o da transição 
das transmissões analógicas para as digitais na televisão terrestre; a que recebemos pelo espectro, sem necessidade do pagamento de assinaturas.

Essa transição não é apenas uma mudança elementar de plataforma técnica de transmissão de sinais de telecomunicações. Ela traz consigo o potencial de uma mudança paradigmática na oferta de conteúdos audiovisuais à sociedade, da qualidade das imagens a quantidade de programações, da multiplicação de serviços prestados ao potencial interativo dos novos serviços. A televisão digital terrestre trazia consigo a possibilidade de uma ampla negociação social que desembocasse em um novo modelo institucional para a nossa comunicação social eletrônica. Ao final, entretanto, de um processo restrito de discussão, quase todo centrado em um estéril embate de padrões e sistemas tecnológicos, o patronato de comunicação obteve do Estado justo o que queria desde o final dos anos 1990.

Transformar uma questão profundamente política em uma decisão eminentemente técnica - e aqui me remeto, no específico, ao argumento teórico geral desta minha fala - foi apenas mais um capítulo de afirmação do poder do empresariado da comunicação sobre o Estado e sobre a esmagadora maioria da sociedade, com a conivência do governo. Como, aliás, sempre aconteceu neste país desde que, em meados de 1962, um ainda economicamente frágil e relativamente desarticulado empresariado de rádio e televisão derrubou 42 vetos que o então presidente João Goulart tinha aposto sobre a Lei $n^{\circ} 4.117$, que ficaria conhecida como Código Brasileiro de Telecomunicações.
Lei sob a qual começa a ser implantada a televisão digital terrestre no Brasil, como se um instrumento regulamentar escrito há quarenta e dois anos fosse suficiente para dotar esse processo de mudança paradigmática em nosso sistema de televisão de políticas minimamente coerentes.

Políticas, registro, que dão - e só elas podem fazê-lo - concretude ao Estado democrático de direito.

A afirmação democrática de direitos no âmbito de um Estado não pode resultar sequer da vontade exclusiva de governos eleitos, quanto mais da vontade de corporações privadas singulares, como é o caso do patronato de comunicação social. Uma política, qualquer política, seja no âmbito da economia, das finanças, da saúde, da educação, da energia, e assim por diante, somente se materializa pela força da lei. Assim o é, ou deveria ser, em todos os setores da vida nacional voltados ao interesse público e ao bem estar social. Assim não o é, entretanto, no setor da comunicação social. Porque a afirmação estatal de direitos nesse setor equivaleria, argumentam os fariseus, a calar a voz do povo, as nossas vozes, com a censura.

Censura maior, entretanto, é a interdição de todo esse debate pelo patronato da comunicação social.

Este é o poder maior que tal patronato exerce sobre a sociedade; o de estabelecer a agenda de discussão pública, eliminando dela qualquer questão que diga respeito a si mesmo, como se uma instituição privado-comercial de comunicação - jornal, revista, rádio, televisão, e seus hoje cada vez mais intrusivos congêneres digitais - estivesse acima do bem e do mal. 
Ampliar nosso lugar, o lugar da comunicação no Estado, é por conseguinte, nos termos postos por este Congresso, o maior desafio.

Pensemos um pouco, juntos, neste momento, em nossa agenda; em parte dela, pelo menos. Aquela decorrente do campo teórico e prático que me é mais familiar; o das políticas de comunicação.

A televisão digital terrestre é, neste caso, a ponta do iceberg, e que me seja relevado o uso da metáfora vulgar. E o é porque, pela polêmica que gerou nos últimos anos, conseguiu vazar em parte para a sociedade. Vazou, registre-se, principalmente a versão laudatória alardeada pelo patronato da comunicação; a que toca apenas nos benefícios da alta definição, e nas possibilidades de se ver televisão em veículos e em telefones celulares. Vazou fundamentalmente o acessório; permaneceu interditado o essencial.

O mais essencial é a política; é aquilo que a sociedade quer para a televisão digital. A política a ser materializada em uma nova legislação setorial; o novo marco regulatório, como também se costuma dizer. Mais de cinco anos, porém, já foram perdidos, nos circuitos especializados, na já referida estéril discussão tecnológica, sem que se avançasse minimamente, mesmo naqueles circuitos, na direção de um novo modelo institucional.

Um novo modelo institucional que, por exemplo, resgatasse aquilo que é a regra geral mesmo nos paises capitalistas centrais - a natureza essencialmente pública da comunicação social. Natureza que, nos casos sempre mais críticos, porque mais universais, do rádio e da televisão, se expressam naqueles países na prioridade normativa que se dá ao público/estatal sobre o privado/ comercial.

Nem vou insistir aqui, como tenho feito em outras circunstâncias, no caso paradigmático, e por isso virtualmente único, do modelo institucional inglês centrado na British Broadcasting Corporation, a BBC tanto do rádio quanto da televisão. Não vou insistir porque ele é distante demais da nossa realidade institucional, ainda que não devamos jamais abandoná-lo como referencial de estudo e pesquisa. Quero me concentrar no modelo institucional estado-unidense, no qual, entre trancos e barrancos, inspiramos o nosso, e que chamo, metaforicamente, de 'modelo CBS/ FCC/PBS'.

CBS para exemplificar a hegemonia, no modelo, do interesse privado comercial; FCC para acentuar a existência nele, desde 1934, de um organismo regulador autônomo, com poderes para frear excessos mercantis; PBS para lembrar a importância de uma rede estatal/ pública autônoma de televisão, que existe desde os anos 1960, nascida de antigas licenças educativas.

Sequer o país mais economicamente capitalista do mundo desenvolveu um modelo de rádio e televisão sem que o Estado dispusesse de forte capacidade reguladora e de um sistema alternativo de produção e distribuição de programações culturais.

Este é, acredito, o patamar mínimo regulamentar e regulatório de que deveríamos partir, no Brasil, antes sequer de se pensar em televisão e rádio digitais.

Como pensar uma radiodifusão digital no Brasil sem que sejam públicos os contratos de concessão já firmados entre a União e 
o patronato do rádio e da televisão privado-comercial? Confesso que às vezes chego a duvidar que esses contratos existam. Mas, se é absurdo se pensar que não existem, não é absurdo acreditar que existem mas não se enquadram em padrões legais mínimos que o direito administrativo brasileiro exige da União para que entregue à exploração privada uma concessão pública. Ainda mais uma concessão pública que se vale de um bem coletivo escasso, como é o caso do espectro radioelétrico.

A sociedade brasileira está na iminência de ver a União entregar sem ônus mais 6 megahertz de espectro para todo o patronato que tiver uma outorga de concessão de televisão sem que disponha dos instrumentos normativos adequados a se ter a certeza da legalidade de tais ações administrativas. Mas, mesmo que venha a se demonstrar que sejam legais essas ações, nos termos de uma legislação escrita há quatro décadas, e já inteiramente modificada para as telecomunicações, elas serão certamente destituídas de qualquer laivo de legitimidade.

Volto agora ao argumento central com o qual tento sustentar teoricamente esta conferência; o de que o ambiente institucional hoje vigente para a comunicação social brasileira, que defino como regulamentarmente disperso e politicamente fragmentado, ignora o valor social do trabalho e privilegia quase que exclusivamente a livre iniciativa.

A idéia de um modelo institucional, que existe, por exemplo, para as universidades públicas brasileiras, ou para o Sistema Único de Saúde, ou para as telecomunicações, ou ainda para a energia elétrica, visa justamente enfrentar os riscos da dispersão regulamentar e da fragmentação política que, como defendo, caracterizam o atual ambiente institucional da comunicação social brasileira.

Dispersão regulamentar e a fragmentação política que começam já na Constituição Federal quando se divide entre os poderes executivo e legislativo a responsabilidade pelas outorgas de rádio e televisão. $\mathrm{Ou}$ quando se divide entre os poderes judiciário e legislativo a cassação de uma outorga de rádio ou televisão. Ou quando se separa radiodifusão, a designação técnica dada aos serviços de rádio e televisão, das telecomunicações, a designação técnica dada aos serviços de telefonia e transmissão de dados que hoje, devido à sua digitalização, convergem aceleradamente com os chamados serviços de radiodifusão. Ou quando se trata a televisão terrestre, gratuita, como radiodifusão, e a televisão por assinatura, paga, como telecomunicações. Ou quando se atribui ao ministério das Comunicações a responsabilidade pela regulação da radiodifusão, e à Agência Nacional de Telecomunicações pela regulação da televisão por assinatura. Ou quase se atribui determinadas responsabilidades de fomento à produção audiovisual a uma agência autônoma destinada a regular a indústria do cinema, misturando regulação e fomento em um mesmo ente administrativo, que, por sua vez, converge e diverge em suas relações com o ministério da Cultura.

Tais dispersões e fragmentações não são fruto de um acaso. Elas nasceram de ações deliberadas do patronato da radiodifusão, levadas a termo principalmente após a Constituição de 1988, de modo a que a sociedade brasileira, por meio 
de representações parlamentares ou autônomas, não tivesse êxito na regulamentação orgânica dos artigos 220 a 224, que compõem o capítulo da Comunicação Social.As regulamentações que aconteceram no período, ou resultaram em medidas no interesse quase exclusivo do patronato, como a da permissão de capital estrangeiro no controle das empresas jornalísticas e de radiodifusão, ou medidas como a da instalação do Conselho de Comunicação Social, que, bandeira de luta de movimentos sociais por mais de dez anos, quando tornada realidade, tornou-se em pouco tempo apenas mais um instrumento de presença hegemônica do referido patronato nas discussões setoriais.

O mais intrigante, neste momento, e faço desta a minha reflexão final, é um repentino interesse daquele patronato no chamado 'marco regulatório' e, em conseqüência, em uma nova lei para a comunicação social eletrônica.

Esse repentino interesse dos radiodifusores pela legalidade não é nem tão repentino, nem incidental.

A convergência de plataformas tecnológicas para oferta de serviços de som, som e imagens, de voz e dados, começa de fato a acontecer. Seja na intenção de uma operadora de telecomunicações oferecer televisão paga por satélite, ou se outra oferecer televisão paga por cabos, ou ainda de uma terceira de oferecer vídeo por demanda com tecnologia de internet. $\mathrm{Ou}$ seja na decisão de uma empresa de televisão, associada a outra de telecomunicações, oferecer, além de televisão paga, também telefonia e acesso à internet.

Ou seja, a realidade técnica e de mercado começa a colidir com a regulamentar e regulatória.

Aquele patronato, então, que se sentia segura com a legislação de 1962, que lhe atribui na prática quase só direitos e raros deveres, volta-se para o Estado e passa a demandar amparo legal. Fala macio, e não mais ameaça com denúncias de volta da censura. Muda de estratégia para sobrepor mais uma vez a livre iniciativa ao valor social do trabalho; põe o consumo que assegura o lucro acima da cidadania que educa e liberta.

O tema deste Congresso, portanto, não poderia ter vindo em melhor hora.

Ele nos atualiza e nos coloca em posição privilegiada de observação e ação sobre a relação Estado / Comunicação quase no exato momento em que mais um ciclo de mudanças profundas começa a incidir sobre aquela relação.

O móvel do ciclo, como já se configurava há uma década, é técnico, e é digital.

Mas, a sua essência é hoje, como foi ontem, e será sempre, política.

Fazer política de comunicação é sempre um vetor significativo na relação Estado/ Comunicação. Talvez o mais significativo neste momento de nossa história. Fazer política de comunicação não é apenas afirmar um direito; o direito à comunicação, que inverte e amplia a idéia clássica do direito à informação. Fazer política de comunicação é, sobretudo, fortalecer a própria idéia do Estado democrático de direito.

Idéia sobre a qual me debrucei hoje movido, como sempre, pelo conhecido e sempre atual aforismo 
de Antonio Gramsci: pessimista? xar que o pessimismo da razão Posso ser, e sou de fato, na razão; predomine sobre o otimismo de mas não posso, não podemos, dei- nossas vontades.

\section{Referências}

ANDERSON, Perry. "Friedrick von Hayek: A direita intransigente no fim do século", In Afinidades Seletivas. São Paulo: Boitempo Editorial, 2002, p. 320.

BOBBIO, Norberto. "A Política". In Norberto Bobbio: o Filósofo e a Política - Antologia. Por José Fernández Santillán (Org.). Rio de Janeiro: Contraponto, 2003, p. 140.

NOGUEIRA, Marco Aurélio. Em Defesa da Política. São Paulo: Editora Senac, 2001, p. 29. 